\title{
Bile bilirubin pigment analysis in disorders of bilirubin metabolism in early infancy
}

W S Lee, P J McKiernan, S V Beath, M A Preece, D Baty, D A Kelly , B Burchell, D J Clarke
Unconjugated hyperbilirubinaemia is an important problem in the neonatal period. Common causes include physiological jaundice, breast milk jaundice, overproduction (that is, polycythaemia), systemic disease (congenital hypothyroidism, sepsis), and inherited disorders of bilirubin metabolism. ${ }^{1}$ These latter include Crigler-Najiar syndrome (CNS) types 1 and 2-caused by a deficiency of hepatic uridine diphosphate glucuronosyl transferase (UGT) and characterised by high serum levels of unconjugated bilirubin that appear in the first few days after birth ${ }^{2}$ - and Gilbert's syndrome. ${ }^{3}$

Accurate diagnosis of Crigler-Najiar syndrome is important because of the implications for prognosis and treatment. Treatment of CNS type 1 consists of the aggressive use of measures to remove bilirubin (either phototherapy or exchange transfusion), while liver transplantation is the definitive treatment. ${ }^{45}$ The major differentiating characteristic between the two types of Crigler-Najiar syndrome is the response to drugs that induce activity of cytochrome P450 enzymes. ${ }^{6-8}$ Phenobarbitone (phenobarbital) causes a significant decline in the serum bilirubin of patients with type 2 disease, with increased hepatic clearance of radiolabelled bilirubin and increased biliary levels of bilirubin diglucuronides. ${ }^{689}$ However, differentiating Crigler-Najjar syndrome type 1 from type 2 solely on the basis of response to phenobarbitone can sometimes be misleading. ${ }^{10}$ Differentiation using bile bilirubin pigment analysis has been recommended. ${ }^{11}{ }^{12}$ In CNS type 1, duodenal bile is practically devoid of bilirubin conjugates. In CNS type 2, bilirubin monoglucuronides are present and some diglucuronides may be detectable during treatment with phenobarbitone. ${ }^{11}{ }^{12}$ In Gilbert's syndrome, bilirubin diglucuronides are the predominant pigment. ${ }^{11}$

The timing of the duodenal aspirate is important. Subsequent management and prognosis depend on an accurate diagnosis, and clinicians are often under pressure to make an early diagnosis. We have reviewed the eventual outcome of children who had bile bilirubin pigment analysis undertaken in early infancy, in order to determine whether early pigment analysis provides useful diagnostic information.

\section{Methods}

We reviewed retrospectively those infants with severe neonatal unconjugated hyperbilirubinaemia who were referred to the liver unit, Birmingham Children's Hospital, between email: pat.mckiernan $a$

bhamchildrens.wmids.nhs.uk

Accepted 20 February 2001

\begin{abstract}
Keywords: bile; bilirubin pigment analysis;
Crigler-Najjar syndrome; Gilbert's syndrome reviewed. gated bilirubin or bilirubin monoconjugates, leading to the incorrect diagnosis of both type 1 and type 2 Crigler-Najjar syndrome.

(Arch Dis Child 2001;85:38-42)
\end{abstract}


1992 and 1999. Common causes of prolonged unconjugated hyperbilirubinaemia were excluded by the referring clinicians. Basic demographic data, family history, onset of jaundice, peak serum bilirubin, and clinical response to phenobarbitone treatment were obtained from the case notes. Abdominal ultrasound and liver biopsies were performed when clinically indicated. The final diagnosis was made on the basis of a combination of results of bile bilirubin pigment analysis, genetic studies, clinical course, and response to phenobarbitone.

\section{COLLECTION OF BILE AND BIOCHEMICAL} ANALYSES

Phototherapy was suspended at least 24 hours before the collection of bile pigment. Bile was collected during upper gastrointestinal endoscopy. The secretion of bile into the duodenum was facilitated by intravenous injection of 1-2 units/kg of cholecystokinin, and $2-5 \mathrm{ml}$ of bile were extracted from the duodenum. The bile aspirates obtained were immediately shielded from light, frozen with liquid nitrogen, and stored at $-80^{\circ} \mathrm{C}$. The bilirubin pigment composition of the bile was determined by high performance liquid chromatography (HPLC) analysis of native tetrapyrolles of unconjugated bilirubin and bilirubin glucuronides at the department of molecular and cellular pathology, Ninewells Hospital, Dundee, Scotland, and the Division of Biological Sciences, University of Huddersfield, England, as previously described. ${ }^{13}$

The reference ranges of bile bilirubin pigments for normal subjects were: unconjugated $0-2 \%$, monoglucuronides $7-16 \%$, diglucuronides $79-91 \%$. Analysis showed that exposure of bile samples to the light source used during the endoscopy procedure had no significant effect on the measured composition of bilirubin pigments (Clarke DJ, Burchell B, unpublished data). Initial diagnosis of CriglerNajjar syndrome type 1 or type 2 or Gilbert's syndrome was made according to the bile bilirubin pigment composition. ${ }^{11}$
GENETIC STUDIES

Genetic studies for Crigler-Najjar syndrome and Gilbert's syndrome were performed as previously described. ${ }^{314}$ Whole blood was obtained and DNA extracted. A homozygosity for a (TA)7TAA (TA7/TA7) has been associated with Gilbert's syndrome. ${ }^{14}$ Crigler-Najjar syndrome types 1 and 2 were diagnosed when there was homozygosity or double heterozygosity for known mutations.

\section{Results}

During the period of 1992 to 1999, nine infants aged less than 3 months with severe unconjugated hyperbilirubinaemia were referred to the hepatology unit, Birmingham Children's Hospital, for further diagnosis. There were five boys and four girls. Eight were delivered at term, while case No 6 was delivered at 36 weeks. Six were white (Europid) and three were born to consanguineous Asian parents originating from the Indian subcontinent. There was no family history of severe neonatal jaundice.

All infants had onset of severe jaundice within first week of life (median 3 days). The peak serum bilirubin ranged from 300 to 650 $\mu \mathrm{mol} / 1$ (median $396 \mu \mathrm{mol} / \mathrm{l}$ ). All required phototherapy, while case No 8 had double exchange transfusions. Four cases (cases 2, 6, 7 , and 9) were started on phenobarbitone at 5 $\mathrm{mg} / \mathrm{kg}$ body weight by their referring clinicians. Five cases were breast fed (cases 3, 4, 5, 7, and 8 ). Case 5 had an atrioventricular septal defect. Three cases (cases 1, 2, and 3) had liver biopsy as part of the diagnostic workup. All were reported as normal histologically.

BILE BILIRUBIN PIGMENT ANALYSIS

The bile bilirubin pigment analyses were performed between ages of 10 and 58 days (median 25 days) (table 1). Based on the results of analyses (first analysis in case 3), there were two infants with CNS type 1, six with CNS type 2, and one with Gilbert's syndrome. Case No 3 had two analyses. The second analysis was carried out seven months after the first, while the patient was treated with phenobarbitone and when the serum bilirubin

Table 1 Demographic data, peak serum bilirubin, and results of bile bilirubin pigment analysis in nine children with prolonged and severe unconjugated hyperbilirubinaemia

\begin{tabular}{|c|c|c|c|c|c|c|c|c|c|c|c|c|}
\hline $\begin{array}{l}\text { Case } \\
\text { No }\end{array}$ & Sex & Ethnicity* & $\begin{array}{l}\text { Onset of } \\
\text { jaundice (days) }\end{array}$ & 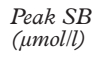 & $\begin{array}{l}\text { Conjugated } \\
S B(\mu \mathrm{mol} / \mathrm{l})\end{array}$ & $\begin{array}{l}\text { UC bilirubin } \\
\text { (umol/l) }\end{array}$ & $\begin{array}{l}\text { Age of bile } \\
\text { analysis (days) }\end{array}$ & $P B$ & $\begin{array}{l}U C(\%) \\
(0-2) \dagger\end{array}$ & $\begin{array}{l}M C(\%) \\
(7-16) \dagger\end{array}$ & $\begin{array}{l}D C(\%) \\
(79-91) \dagger\end{array}$ & Diagnosis \\
\hline 1 & M & European & 1 & 431 & 0 & 431 & 19 & - & 100 & 0 & 0 & CNS 1 \\
\hline 2 & $\mathrm{~F}$ & European & 4 & 396 & 2 & 394 & 38 & + & 19 & 81 & 0 & CNS 2 \\
\hline 3 & M & Asian & 3 & 650 & 10 & 640 & $\begin{array}{l}25 \\
8 \mathrm{~m}\end{array}$ & + & $\begin{array}{l}100 \\
1\end{array}$ & $\begin{array}{l}0 \\
91\end{array}$ & $\begin{array}{l}0 \\
8\end{array}$ & CNS 1 \\
\hline 4 & M & European & 2 & 300 & 0 & 300 & 25 & - & 2 & 34 & 64 & Gilbert \\
\hline 5 & $\mathrm{~F}$ & Asian & 1 & 456 & 20 & 436 & 18 & - & 36 & 57 & 7 & CNS 2 \\
\hline 6 & $\mathrm{~F}$ & European & 6 & 390 & 10 & 380 & 33 & + & 4 & 64 & 31 & \\
\hline 7 & M & European & 2 & 340 & 20 & 320 & 58 & + & 25 & 46 & 29 & \\
\hline 8 & M & European & 5 & $>500$ & 0 & $>500$ & 10 & - & 20 & 53 & 27 & \\
\hline 9 & $\mathrm{~F}$ & Asian & 4 & 389 & 19 & 380 & 41 & + & 43 & 26 & 31 & \\
\hline 10 & M & European & 5 & - & - & - & $13 \mathrm{y}$ & - & 1 & 18 & 82 & \\
\hline 11 & $\mathrm{~F}$ & European & $2-3 y$ & - & - & - & $16 \mathrm{y}$ & - & 4 & 18 & 78 & \\
\hline 12 & M & European & 5 & 403 & 20 & 383 & $13 \mathrm{y}$ & + & 14 & 80 & 5 & \\
\hline 13 & M & European & $16 \mathrm{y}$ & 63 & 21 & 52 & $16 \mathrm{y}$ & - & 12 & 70 & 18 & \\
\hline
\end{tabular}

*The three Asians infants were born to consanguineous parents.

†Reference range for normal individuals (Clarke DJ, Burchell B, unpublished data).

$\ddagger$ Diagnoses based on analysis of bile bilirubin pigments.

TSecond analysis performed at 8 months of age while on phenobarbitone.

CNS 1, Crigler-Najiar type 1; CNS 2: Crigler-Najjar type 2; DC, bilirubin diglucuronides; $\mathrm{m}$, months; MC, bilirubin monoglucuronides; PB, phenobarbitone treatment during bile bilirubin analysis $(+$, on phenobarbitone, - , not on phenobarbitone); SB, serum bilirubin; UC, unconjugated; y, years. 
Table 2 Initial diagnosis, response to phenobarbitone, genetic studies, and final diagnosis

\begin{tabular}{|c|c|c|c|c|c|}
\hline Case & Initial diagnosis & Response to $P B$ & Genetic studies & Follow up and outcome & Final diagnosis \\
\hline 1 & CNS 1 & None & a & $\begin{array}{l}\text { Phototherapy } 10 \mathrm{~h} / \text { day; awaiting liver } \\
\text { transplant }\end{array}$ & CNS 1 \\
\hline 2 & CNS 2 & Good & b & On PB; SB $\sim 78-139 \mu \mathrm{mol} / 1$ & CNS 2 \\
\hline 3 & CNS 1 & Good & & $\begin{array}{l}\text { Phototherapy discontinued at } 1 \text { year; SB } \\
\sim 90-110 \mu \mathrm{mol} / 1 \text { while on } \mathrm{PB}\end{array}$ & CNS 2 \\
\hline 4 & Gilbert & Good & & PB for 1 week; SB $33 \mu \mathrm{mol} / 1$ while not on PB & Gilbert \\
\hline 5 & CNS 2 & Good & & Not on PB, SB $9 \mu \mathrm{mol} / 1$ & Gilbert/normal? \\
\hline 6 & CNS 2 & Good & & SB normalised after stopping PB & Gilbert/normal? \\
\hline 7 & CNS 2 & Good & & $\begin{array}{l}\mathrm{PB} \times 14 \mathrm{~d} \text {; SB } 17 \mu \mathrm{mol} / 13 \text { months after } \\
\text { discontinuing PB }\end{array}$ & Gilbert/normal? \\
\hline 8 & CNS 2 & Good & 'TA6/TA6 & SB $10 \mu \mathrm{mol} / 1$ after discontinuing PB & Normal \\
\hline 9 & CNS 2 & Good & TA6/TA6 & Clinically not jaundiced, not on PB & Normal \\
\hline 10 & Gilbert & & TA6/TA $7^{\mathrm{d}}$ & Not on PB & Gilbert \\
\hline 11 & Gilbert & & & Not on PB & Gilbert \\
\hline 12 & CNS 2 & Good & & On PB, PB $150 \mu \mathrm{mol} / 1$ & CNS 2 \\
\hline 13 & Gilbert & & & Not on PB & Gilbert \\
\hline
\end{tabular}

aDouble heterozygous: $\mathrm{G} \rightarrow \mathrm{C}$ mutation at nucleoside 923 of exon 2 of $U G T 1 A 1$, and $\mathrm{T}$ residue deletion at nucleoside 1221 at exon 4 . ${ }^{b}$ Heterozygous for $\mathrm{C} \rightarrow \mathrm{T}$ mutation at nucleoside 625 of exon 1 of $U G T 1 A 1$.

'Negative for CNS mutation in addition to homozygous TA6/TA6, which is not associated with Gilbert's syndrome.

${ }^{\mathrm{d}}$ Father, paternal grandmother, and uncle have TA7/TA7, which has been associated with Gilbert's syndrome.

CNS 1, Crigler-Najjar syndrome type 1; CNS 2, Crigler-Najjar syndrome type 2; PB, phenobarbitone; SB, serum bilirubin.

had fallen to $80 \mu \mathrm{mol} / 1$. There was a marked reduction in the unconjugated bilirubin with a substantial increase in the monoglucuronides.

For comparison, the results of bile bilirubin pigment analysis of four patients older than 3 months, who were referred to the liver unit for investigations of the underlying cause of jaundice, are also shown in table 1 . Cases 10 and 11 were investigated for intermittent jaundice, with a clinical diagnosis of Gilbert's syndrome. Case 12 was diagnosed clinically as CNS type 2 with persistent jaundice. The serum bilirubin was $150 \mu \mathrm{mol} / \mathrm{l}$, mainly unconjugated while on phenobarbitone. Case 13 was first noticed to be jaundiced at the age of 16 , after an episode of acute gastroenteritis. The serum bilirubin was $63 \mu \mathrm{mol} / \mathrm{l}$, with unconjugated bilirubin $52 \mu \mathrm{mol} / 1$.

\section{GENETIC STUDIES}

Genetic studies were performed in four cases (cases 1, 2, 8, and 9). Two cases (case 8 and 9) were homozygous UGT1A1 TA6/TA6, which is not associated with hyperbilirubinaemia. Case 1 showed a heterozygous G-to-C mutation in exon 2 at nucleotide position 923 of the UGT1A1 gene, which results in a glycine to alanine change at codon 308. A second heterozygous mutation was found where there was a $\mathrm{T}$ residue deletion at nucleoside 1221 (1221delT) in exon 4. Case 1 has inherited two defective UGT1A1 alleles from each parents, resulting in complete loss of bilirubin UGT activity and CNS type 1 . Case 2 showed a heterozygous C-to-T mutation at nucleotide position 625 of the UGT1A1 gene and a heterozygous IVS4-1G-to-A mutation. In addition she is also heterozygous for $U G T 1 A 1$ promoter alleles TA6/TA7. Neither TA6/TA6 nor TA6/ TA7 are known to be associated with hyperbilirubinaemia.

\section{CLINICAL COURSE AND EVENTUAL DIAGNOSES}

These data are shown in table 2. Diagnosis of six cases needed to be reviewed. Case 3, with unconjugated bilirubin and no mono- or diglucuronides in the bile, was initially diagnosed as CNS type 1. Phenobarbitone was started and phototherapy was continued. Serum bilirubin fell to $40-60 \mu \mathrm{mol} / 1$, and the duration of phototherapy shortened progressively. A second bile bilirubin pigment analysis, performed at 8 months of age, showed predominantly monoglucuronides. The diagnosis was revised to CNS type 2. Presently, at 5 years of age, the serum bilirubin is maintained in the range of 50-90 $\mu \mathrm{mol} / 1$ while on phenobarbitone.

Five cases (cases 5, 6, 7, 8, and 9), which had an initial diagnosis of CNS type 2, had resolution of jaundice and a fall in serum bilirubin following treatment with phenobarbitone. They have all had normal serum bilirubin since discontinuation of phenobarbitone. In addition, both case 8 and case 9 had negative genetic studies for the Crigler-Najjar syndrome mutation and Gilbert's syndrome (TA6/ TA6). Case 6, who belonged to a travelling family, was given phenobarbitone for one week. The serum bilirubin continued to fall after phenobarbitone was discontinued. The final diagnosis was thought to be physiological jaundice or Gilbert's syndrome. In contrast, in all the four cases who had bile bilirubin pigment analysis done after 3 months of age, the diagnosis that was made on the basis of the results of bile bilirubin pigment analysis concurred with the clinical diagnosis.

\section{Discussion}

The diagnosis of Crigler-Najjar syndrome types 1 and 2 and Gilbert's syndrome can usually be made from a combination of response to phenobarbitone, bile bilirubin pigment analysis, and genetic studies. ${ }^{15}$ In vitro measurement of UGT activity in liver biopsy tissue to differentiate CNS type 1 from CNS type 2 is complex and not routinely available. ${ }^{16}$ Phenobarbitone treatment reduces serum bilirubin by $26 \%$ or more in CNS type 2, while no reduction occurs in type $1 .{ }^{11}$ However, there are some exceptions to this observation, ${ }^{16}$ and in addition, the reduction in serum bilirubin may not be apparent within a few months after starting treatment. ${ }^{10}$

Sinaasappel et al performed bile bilirubin pigment analysis in nine patients with CriglerNajjar syndrome (four type 1 and five type 2), aged between 1 and 18 years, and concluded that the two types could be differentiated on 
the basis of bile bilirubin pigment analysis. ${ }^{11}$ However, such a delay in confirming the diagnosis is unacceptable in clinical practice, as clinicians usually face enormous pressure from parents to confirm or exclude the possibility of CNS type 1, especially in view of the eventual need for a liver transplant. Hence it would seem reasonable to perform bile bilirubin pigment analysis at a much younger age, especially during early infancy, when the majority of patients would still have significant jaundice.

However, before recommending routine analysis of bile bilirubin pigments in early infancy, the effect of maturation of UGT needed to be considered. Ciotti et al observed a delayed response to phenobarbitone in a child with CNS type 2, who was initially diagnosed as type 1 because of non-response to phenobarbitone for the first 7 months of life. ${ }^{10}$ They attributed such delay to a simple developmental phenomenon, causing slow development of the secondary structural changes necessary for UGT activity. Such a developmental phenomenon could explain the observations made in this study that bile bilirubin pigment analysis performed early in life showed low levels of unconjugated bilirubin and monoglucuronides in the bile because of relatively low activity of the enzyme UGT. With maturation and the introduction of phenobarbitone, the process of glucuronidation increased and the serum bilirubin fell. Rubaltelli et al observed that with phenobarbitone treatment there was an absolute increase in the monoglucuronide concentration but not the diglucuronide concentration in the bile. ${ }^{12}$ We observed that in case 3, after phenobarbitone treatment, there was a

Unconjugated hyperbilirubinaemia

(PB $>200 \mu \mathrm{mol} / \mathrm{l}$, mainly unconjugated)

exclude common causes

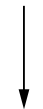

Start phenobarbitone ( $5 \mathrm{mg} / \mathrm{kg}$ body weight)

continue phototherapy if $\mathrm{SB}>250 \mu \mathrm{mol} / \mathrm{l}$

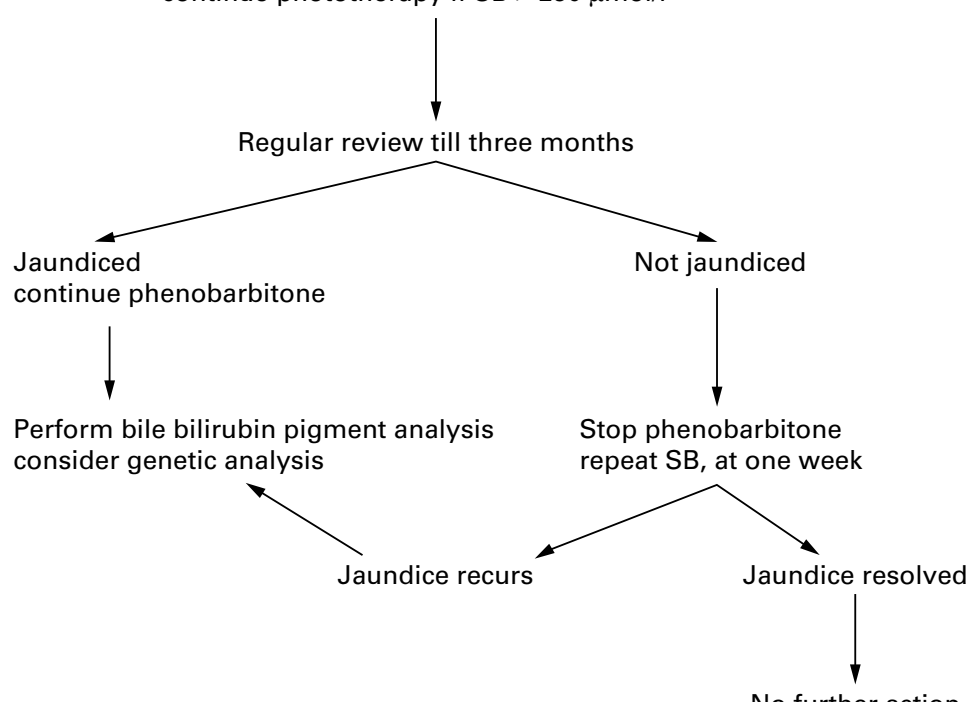

Figure 1 Proposed schematic investigation of prolonged unconjugated hyperbilirubinaemia. $S B$, serum bilirubin. significant increase in both the mono- and diglucuronides in the bile.

We have shown that while bile aspirate for bilirubin pigment analysis can be performed with relative ease and safety during the first 3 months of life, analysis of bile bilirubin pigment at such a young age often showed high levels of unconjugated or monoconjugated bilirubin in the bile. As outlined above, this reflects the immaturity of hepatocytes at a very young age, leading to relative UGT deficiency. It has been shown previously that UGT activity is low in the neonatal period and increases gradually to adult values after 3 months of age. ${ }^{17}$ This immaturity had led to overestimation of the severity of the disease and an overdiagnosis of the Crigler-Najjar syndrome, both type 1 and type 2 , in our cases. A subsequent review of the initial diagnoses was necessary in six of nine instances. In five cases, normalisation of serum bilirubin after discontinuation of phenobarbitone made the diagnosis of CNS type 2 unlikely. In case 3, who had had two analyses of bile bilirubin pigments, the second analysis showed a marked increase of bilirubin monoglucuronides and reduced unconjugated bilirubin compared with the first analysis, which consisted of predominantly unconjugated bilirubin.

In case 2, whose initial diagnosis of CNS type 2 concurred with the final diagnosis, bile bilirubin pigment analysis was performed when the patient was on phenobarbitone. In case 3-who had a second bile bilirubin analysis that showed predominantly a monoglucuronide, consistent with the clinical picture of CNS type 2-the bile bilirubin pigment analysis was performed after phenobarbitone was started. It would therefore be reasonable to recommend performing bile bilirubin pigment analysis while the patient is on phenobarbitone.

In has been shown convincingly that mutations in the UGT1 gene- the gene locus encoding the enzyme UGT in patients with CNS type 1 -are responsible for abolishing the hepatic UGT activity in vitro in COS cells. ${ }^{18}$ Mutation analysis for both Crigler-Najjar syndrome and Gilbert's syndrome is now available. ${ }^{19}$ This is useful for confirmation of the clinical diagnosis and for genetic counselling, but is complicated and not routinely available. ${ }^{15}$ The only CNS type 1 case in this series was shown to be a double heterozygote for mutations responsible for CNS type 1 . In addition, two patients with initial diagnosis of CNS type 2, but who subsequently had normal levels of serum bilirubin without phenobarbitone, were found to be homozygous of TA6/TA6, which is not associated with Gilbert's syndrome.

As a result of this study, we subsequently reviewed the policy of investigating children with prolonged unconjugated hyperbilirubinaemia. The protocol has been revised to avoid performing bile bilirubin pigment analysis too early and thereby overdiagnosing CriglerNajiar syndrome types 1 and 2. After excluding other more common causes of unconjugated hyperbilirubinaemia, a therapeutic trial of phenobarbitone at a dose of $5 \mathrm{mg} / \mathrm{kg}$ body weight should be started while continuing phototherapy if necessary (fig 1). Such patients 
should then be repeatedly reviewed; if by 3 months of age there is persistent elevation of unconjugated serum bilirubin, vigorous treatment with phototherapy and phenobarbitone should be continued. Bile bilirubin pigment analysis should be delayed until after 3 months of age. Although genetic studies may be useful, currently they are complex to perform and not routinely available, but they can be done if there is a particular concern.

1 Roberts EA. The jaundiced baby. In: Kelly DA, ed. Diseases of the liver and biliary system in children. London: Blackwell Science, 1999:11-45.

2 Crigler JF, Najjar VA. Congenital familial nonhemolytic jaundice with kernicterus. Pediatrics 1952;10:169-79.

3 Monaghan G, McLellan A, McGeehan A, et al. Gilbert's syndrome is a contributory factor in prolonged unconjugyated hyperbilirubinemia of the newborn. If Pediatr gated hyperbilirub

4 Sokal EM, Silva ES, Hermans D, et al. Orthotopic liver transplantation for Crigler-Naijar type I disease in six chiltransplantation for Crigler-Najiar type

5 van der Veere CN, Sinaasappel M, McDonagh AF, et al. Current therapy for Crigler-Najiar syndrome type 1: report of a world registry. Hepatology 1996;24:311-15.

6 Kreek MJ, Sleisenger MH. Reduction of serum unconjugated bilirubin with phenobarbitone in adult nonhaemolytic unconjugated hyperbilirubinaemia. Lancet 1968;ii:73-8.

7 Crigler JF, Gold NI. Effect of phenobarbital on bilirubin metabolism in an infant with congenital, nonhemolytic unconjugated hyperbilirubinaemia, and kernicterus. 7 Clin Invest 1969;48:42-55.

8 Black M, Fevery J, Parker D, et al. Effect of phenobarbitone on plasma ${ }^{14} \mathrm{C}$ bilirubin clearance in patients with unconjugated hyperbilirubinaemia. Clin Sci Mol Med 1974;46:1-17.
9 Gordon ER, Shaffer EA, Sass-Kortsak A. Bilirubin secretion and conjugation in the Crigler-Naijar syndrome type 2 . Gastroenterology 1976;70:761-5.

10 Ciotti M, Werlin SL, Owens IS. Delayed response to phenobarbital treatment of a Crigler-Najjar type II patient with partially inactivating missense mutations in the bilirubin UDP-glucuronosyltransferase gene. $\mathcal{F}$ Pediatr Gastroenterol Nutr 1999;28:210-13.

11 Sinaasappel M, Jansen PLM. The differential diagnosis of Crigler-Najiar Disease, type 1 and 2, by bile pigment analysis. Gastroenterology 1991;100:783-9.

12 Rubaltelli FF, Novello A, Zancan L, et al. Serum and bile bilirubin pigments in the differential diagnosis of CriglerNajiar Disease. Pediatrics 1994;94:553-6.

13 Odell GB, Mogilevsky WS, Gourley GR. High-performance liquid chromatographic analysis of bile pigments as their native tetrapyrroles and as their dipyrrolic azosulfanilate derivatives. F Chromatogr 1990;529:287-98.

14 Clarke DJ, Moghrabi N, Monaghan G, et al. Genetic defects of the UDP-glucuronyltransferase-1 (UGT1) gene that cause familial non-haemolytic unconjugated hyperbilirubinaemias. Clin Chim Acta 1997;266:63-74.

15 Jansen PLM. Diagnosis and management of Crigler-Najjar syndrome. Eur F Pediatr 1999;158(suppl 2):S89-94.

16 Seppen J, Bosma PJ, Goldhoorn BG, et al. Discrimination between Crigler-Najiar type I and II by expression of mutant bilirubin uridine diphosphateglucuronosyltransferase. $\mathcal{F}$ Clin Invest 1994;94:2385-91.

17 Onishi S, Kawade N, Itoh S, et al. Postnatal development of uridine diphosphate glucuronyltransferase activity towards bilirubin and 2-aminophenol in human liver. Biochem 7 1979;184:705-7.

18 Erps LT, Ritter JK, Herch JH, et al. Identification of two single base substitution in the UGT1 gene locus bilirubin diphosphate glucurosyltransferase activity in vitro. $\mathcal{F}$ Clin Invest 1994,93:564-70.

19 Sampietro M, Iolascon A. Molecular pathology of CriglerNajjar type I and II and Gilbert's syndromes. Haematologica 1999;84:150-7.

\title{
Narrative Based Medicine, An Interdisciplinary Conference
}

\author{
Research, Narrative, and Practice
}

A two day conference-Monday 3rd and Tuesday 4th September 2001

\section{Homerton College, Cambridge, UK}

BMF Publishing Group

For full details contact: BMA/BMJ Conference Unit, Tavistock Square, London, WC1H 9JP Tel: +44 (0)20 7383 6819; fax: +44 (0)207383 6663; email: clyders@bma.org.uk. www.quality.bmjpg.com 